OPEN ACCESS

Edited by:

Bo Li,

University of Nottingham Ningbo

China, China

Reviewed by:

Kequan Yu,

University of Michigan, United States

Luciano Ombres,

University of Calabria, Italy

*Correspondence:

Shuai Fang

fangshuai@scut.edu.cn

P. L. Ng

irdngp/@gmail.com

Specialty section:

This article was submitted to

Structural Materials,

a section of the journal

Frontiers in Materials

Received: 31 May 2020

Accepted: 21 July 2020

Published: 21 August 2020

Citation:

Zhu C-J, Fang S, Ng PL, Pundiené I and Chen J-J (2020)

Flexural Behavior of Reinforced

Concrete Beams Strengthened by

Textile Reinforced Magnesium

Potassium Phosphate Cement

Mortar. Front. Mater. 7:272.

doi: 10.3389/fmats.2020.00272

\section{Flexural Behavior of Reinforced Concrete Beams Strengthened by Textile Reinforced Magnesium Potassium Phosphate Cement Mortar}

\author{
Cheng-Jie Zhu',2, Shuai Fang ${ }^{3 *}$, P. L. Ng ${ }^{2,4 *}$, Ina Pundiené ${ }^{2}$ and Jia-Jian Chen ${ }^{5}$ \\ ${ }^{1}$ College of Civil Engineering, Yancheng Institute of Technology, Yancheng, China, ${ }^{2}$ Institute of Building Materials, Vilnius \\ Gediminas Technical University, Vilnius, Lithuania, ${ }^{3}$ School of Civil Engineering and Transportation, South China University \\ of Technology, Guangzhou, China, ${ }^{4}$ Department of Civil Engineering, The University of Hong Kong, Hong Kong, China, \\ ${ }^{5}$ Department of Civil Engineering, Foshan University, Foshan, China
}

Magnesium potassium phosphate cement (MKPC), made of sintered magnesium oxide and potassium phosphate, is a new material for construction and structural repair. It possesses high early strength and bond capacity, low drying shrinkage, excellent fire resistance and compatibility with concrete. These characteristics render it an ideal material for strengthening reinforced concrete $(R C)$ structures. This study developed a MKPC-based textile reinforced cementitious composite (TRCC) to strengthen RC beams at soffit. Three-point flexural tests were conducted on two control specimens without strengthening and two strengthened specimens. Experimental results showed that the TRCC system exhibits good bonding with substrate concrete. The strengthened specimens failed due to rupture of textile meshes in TRCC. TRCC could improve load capacity by $4-25 \%$, postpone propagation of cracks, reduce tensile strain of main reinforcement and reduce deflection of beams at the same load level. High relative textile ratios contributed to the load resistance while impaired the ductility of strengthened beams. Design formulae are proposed to predict the flexural capacity of beams strengthened by MKPC-based TRCC, and reasonable prediction close to experimental results can be obtained from the formulae.

Keywords: flexural ductility, flexural strengthening, magnesium potassium phosphate cement, relative textile ratio, textile reinforced cementitious composite

\section{INTRODUCTION}

Reinforced concrete (RC) structures are susceptible to structural deterioration due to aging, earthquake, fire, and chemical corrosion. Researchers and engineers have been seeking effective and economical methods for strengthening deteriorated structures. A new textile reinforced cementitious composite (TRCC) strengthening system has drawn attention recently (Bernat et al., 2013; Escrig et al., 2015; Mesticou et al., 2017; Ortlepp and Ortlepp, 2017; Holschemacher et al., 2018). It consists of cementitious matrix reinforced with textile meshes, and it possesses good performance under both compression and tension (Triantafillou, 2016). TRCC has advantages of 
desirable durability, ease of construction and high strengthening efficiency (Yin, 2010; Cao, 2015; Holschemacher, 2020). The cementitious binder of TRCC has excellent durability, fire resistance and compatibility with concrete structures (Xu et al., 2016; Kong et al., 2017; Tran et al., 2018). The common fibers used in TRCC, such as carbon fiber, alkali-resistant (AR) glass fiber, aramid fiber and basalt fiber, possess outstanding corrosion resistance (Mobasher, 2019; Peled et al., 2019). This enables adoption of thin cover for TRCC, which can least affect the original dimensions of members due to strengthening (Hegger and Voss, 2008; Yin et al., 2019). In addition, the orientations and layers of textile meshes can be easily adjusted according to the stress distribution of strengthened members (Bruckner et al., 2006). The above-mentioned advantages facilitate the application of TRCC in structural repair and strengthening (Naaman, 2010).

Different researchers have conducted studies on the mechanical performance of TRCC strengthened RC members. They found that TRCC can effectively enhance the cracking load, yield load and ultimate load of RC beams (Zhang, 2009; Xun et al., 2010; Zhi et al., 2017). In comparison with FRP (fiberreinforced polymer) system, TRCC strengthening was reported to exhibit a slightly inferior improvement in load capacity, but better crack resistance and more ductile failure mode than FRP (Yin et al., 2015; Raoof et al., 2017). Kolsch (1998) indicated that the bond between TRCC and substrate concrete acts as a critical factor for effective repair and strengthening. According to Zhang (2009) and Xun et al. (2010), upon increasing the textile mesh ratios to a certain level, the bond becomes a limiting factor controlling the load capacity of strengthened members.

Magnesium potassium phosphate cement (MKPC) is made of sintered magnesium oxide and potassium phosphate (Gardner et al., 2015; Le Rouzic et al., 2017; Yang et al., 2020). As compared with ordinary Portland cement, MKPC has higher bond strength, lower drying shrinkage, faster setting and better abrasive resistance, which makes MKPC a highly competitive binder for TRCC system (Cao, 2015; Du et al., 2017). This study put forward a new strengthening scheme using MKPC-based TRCC and investigated its strengthening effect on RC beams. Control and strengthened RC beams were produced and subjected to flexural tests. The experimental results exhibited good agreement with the design formulae for flexural strengthening proposed in this research.

\section{EXPERIMENTAL INVESTIGATION}

\section{Materials and Specimens}

The component materials for preparation of TRCC included MKPC paste (used as bond coat applied onto the substrate concrete) and MKPC mortar (applied upon placing each layer of textile mesh), and fabric textile meshes. The ingredients and mix proportions of MKPC paste and mortar can be referred to the research works by $\mathrm{Gu}$ (2019), and are complying with the requirements in Chinese Standard JC/T 2537-2019 (Ministry of Industry and Information Technology of the People's Republic of China [MOIIT], 2019). The mix proportions of the MKPC paste and mortar, and their mean flexural strengths and mean compressive strengths at 28 days are given in Table 1. The flexural strengths of MKPC paste and mortar were measured from $40 \mathrm{~mm} \times 40 \mathrm{~mm} \times 160 \mathrm{~mm}$ prism specimens under a loading rate of $50 \pm 10 \mathrm{~N} / \mathrm{s}$ according to International Standard ISO 679 (International Organization for Standardization, 2009). Following the same standard, the compressive strengths were measured from the broken prism specimens under a loading rate of $2400 \pm 200 \mathrm{~N} / \mathrm{s}$. It is noted that the MKPC paste and mortar had higher compressive strength compared to the concrete of the specimen beams, but not excessively high to render the MKPC materials suitable for use in strengthening without compatibility problem.

The fabric textile meshes were woven orthogonally with carbon and AR glass fabric bundles. The former possessed excellent mechanical performance and contributed mainly to load capacity enhancement of strengthened structural members, while the latter was of lower cost and could sustain larger elongation. Table 2 summarizes the characteristics of textile meshes, of which the tensile properties were measured in laboratory according to the requirements in Chinese Standard GB/T 3362-2017 (General Administration of Quality Supervision, Inspection and Quarantine of the People's Republic of China [GAQSIQ], 2017). The meshes were cut into pieces with dimensions of $1500 \times 150 \mathrm{~mm}$, in which carbon fabric bundles were aligned along the longitudinal direction of the beam member. Intervals between fabric bundles were $15 \mathrm{~mm}$ in both directions. In order to keep the textile meshes parallel to soffit surface and even out the load distribution among the fabric bundles, the meshes were stiffened by impregnation in epoxy resin. The fabric bundles were maintained straight during the curing and hardening of epoxy resin.

The beam specimens were $2000 \mathrm{~mm}$ long and had a uniform cross section of $150 \mathrm{~mm}$ (breadth) $\times 250 \mathrm{~mm}$ (depth). Reinforcements of specimen consisted of two main reinforcing bars at tension side, two hanger bars and 16 stirrups. The stirrups had center-to-center spacing of $200 \mathrm{~mm}$ at the mid-span region and $100 \mathrm{~mm}$ approaching both ends of specimens (Figure 1). Deformed steel bars with diameters of 10 and $16 \mathrm{~mm}$ (D10 and

TABLE 1 | Mix proportions and strength of MKPC paste and mortar.

\begin{tabular}{lcc}
\hline & MKPC paste & MKPC mortar \\
\hline Magnesium oxide & 0.8 & 0.8 \\
Fly ash & 0.1 & 0.1 \\
Metakaolin & 0.1 & 0.1 \\
Potassium dihydrogen phosphate & 0.4 & 0.667 \\
Borax & 0.025 & 0.02 \\
Disodium hydrogen phosphate & 0.07 & 0.08 \\
Inorganic chloride-containing salt & 0.03 & 0.04 \\
Sodium silicate solution & 0.031 & 0.036 \\
Water & 0.229 & 0.325 \\
Sand & - & 1.25 \\
28-day flexural strength (MPa) & 8.13 & 6.97 \\
28-day compressive strength (MPa) & 50.15 & 61.69
\end{tabular}

In the mix proportions, the values shown are mass ratios with respect to the contents of (Magnesium oxide + Fly ash + Metakaolin). 
TABLE 2 | Characteristics of textile mesh.

\begin{tabular}{|c|c|c|c|c|c|}
\hline Fiber direction & Fiber type & Sectional area ( $\mathrm{mm}^{2} /$ bundle) & Tensile strength $\boldsymbol{f}_{c f}(\mathrm{MPa})$ & Elastic modulus (GPa) & Elongation \\
\hline Longitudinal & Carbon fiber & 0.45 & 2184.4 & 236 & $1.2 \%$ \\
\hline Transverse & AR glass fiber & 0.58 & 698.3 & 65 & $2.5 \%$ \\
\hline
\end{tabular}

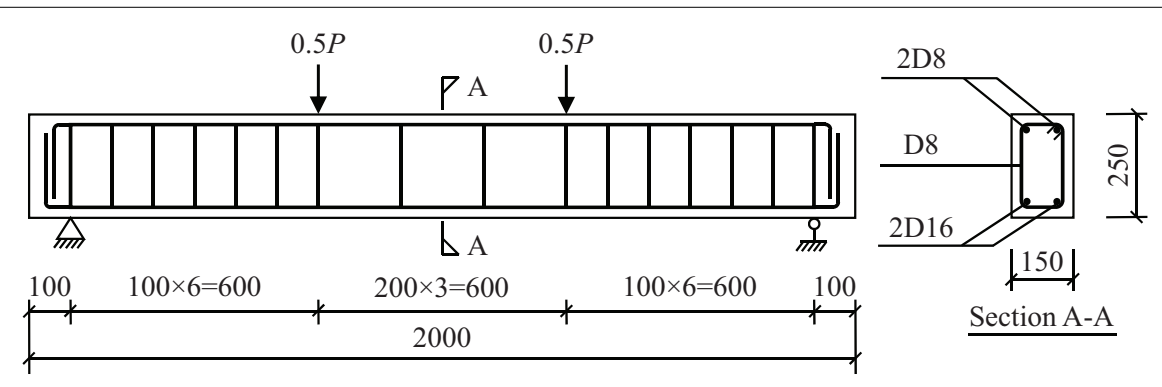

FIGURE 1 | Schematic view of specimen L-0-2 (unit: mm).

TABLE 3 | Details of main reinforcements and textile meshes.

\begin{tabular}{|c|c|c|c|c|c|}
\hline Specimen & Main reinforcement & Main reinforcement ratio & Layer of textile mesh & Textile ratio & Relative textile ratio \\
\hline$L-0-1$ & 2D10 & $0.494 \%$ & - & - & - \\
\hline LD-3 & 2D10 & $0.494 \%$ & 3 & $0.047 \%$ & $9.51 \%$ \\
\hline$L-0-2$ & 2D16 & $1.283 \%$ & - & - & - \\
\hline LD-2 & 2D16 & $1.283 \%$ & 2 & $0.032 \%$ & $2.49 \%$ \\
\hline
\end{tabular}

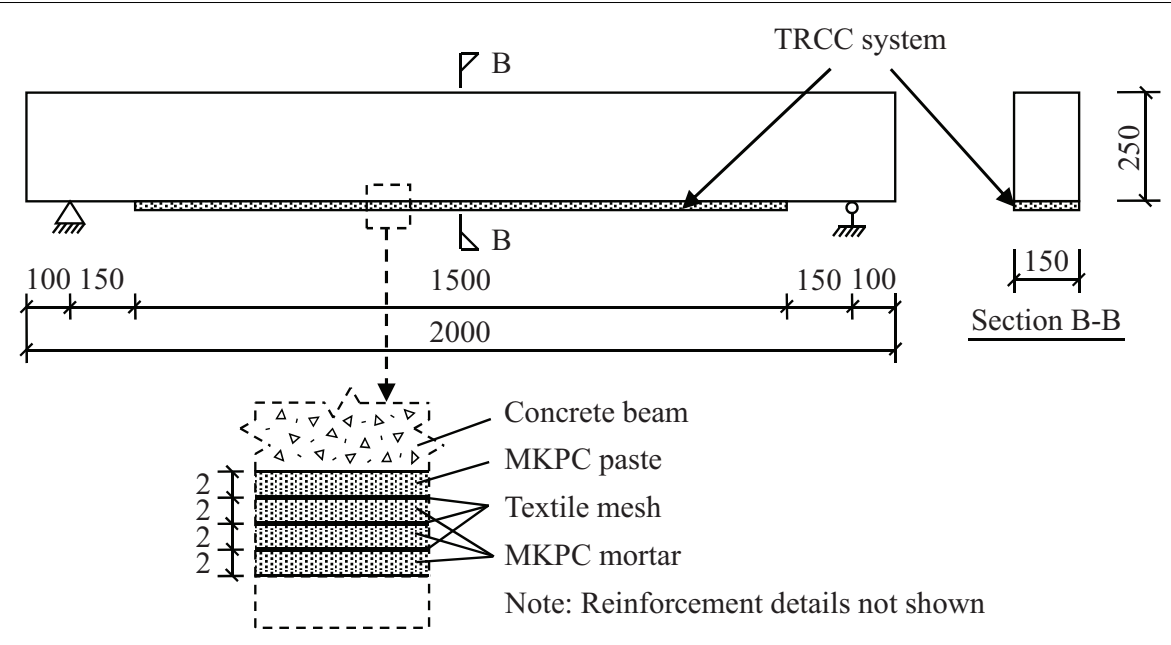

FIGURE 2 | Schematic view of strengthened specimen (unit: $\mathrm{mm}$ ).

D16) were used as the main reinforcements of RC beams. Plain steel bars with diameter of $8 \mathrm{~mm}$ (D8) were used as hanger bars and stirrups. The average yield strength of D8, D10, and D16 bars were measured from tensile testing in laboratory to be 479.34, 511.20 , and 534.25 MPa, respectively. Concrete cover for stirrups was $25 \mathrm{~mm}$. The 28-day mean compressive strength of concrete measured from $150 \mathrm{~mm}$ cubes was $44.77 \mathrm{MPa}$.

Four RC beam specimens were prepared. Two beams (L0-1 and L-0-2) with different main reinforcement ratios were designated as control specimens. The remaining two specimens
(LD-3 and LD-2) were strengthened using TRCC with three and two layers of meshes, respectively. Table 3 summarizes the main reinforcement and textile mesh details of the specimens. Specimens L-0-1 and LD-3 had the same main reinforcement ratio, whereas specimens L-0-2 and LD-2 had the same main reinforcement ratio. Main reinforcement ratios and textile ratios are defined as the ratios of sectional area of main reinforcements and longitudinal fabric bundles to the effective area of beam section, respectively. Relative textile ratio denotes the sectional area ratio of longitudinal fabric bundles to main reinforcements. 


\section{Strengthening}

Strengthening with TRCC was applied to specimens LD-3 and LD-2. The strengthening work consisted of the following steps. Firstly, the specimens were inverted with their soffits facing upwards. The soffit surface was then mechanically chiseled for roughening. The chiseled region had a length of $1500 \mathrm{~mm}$ and a width of $150 \mathrm{~mm}$ (Figure 2). MKPC paste with thickness of $2 \mathrm{~mm}$ was applied on the chiseled region as the bond coat for better surface bonding. One layer of impregnated textile mesh was laid on the MKPC paste. Subsequently, MKPC mortar with thickness of $2 \mathrm{~mm}$ was applied to cover the mesh. The preceding steps of laying the textile mesh and covering with MKPC mortar were repeated until the required number of textile mesh layers was completed. Figure 2 illustrates the strengthening scheme. After final setting, the MKPC-based TRCC were kept dampened for 28 days.

\section{Experimental Setup}

Strain gauges were installed on main reinforcements. Displacement gauges were installed at mid-span and support positions to record the deflection of beam specimens. Threepoint flexural tests were performed on the specimens. Figure 3 depicts the schematic view of the flexural test. During the test, monotonic load with an increment step of $5 \mathrm{kN}$ was applied to the specimens. The tests were terminated when the specimens failed to carry the imposed load.

\section{RESULTS AND DISCUSSION}

\section{Failure Modes}

Both control specimens L-0-1 and L-0-2 exhibited typical bending failure. As the load increased, the cracks initiated at the soffit of specimens and propagated upwards. The cracks were distributed in pure bending zone of the specimens. When the load reached the yielding level, main reinforcements yielded and deflection of specimens rapidly increased. Finally the concrete in the compression region of specimens crushed (Figures 4A,C).

For the strengthened specimens LD-3 and LD-2, benefited from the structural resistance of TRCC, the flexural strengthening

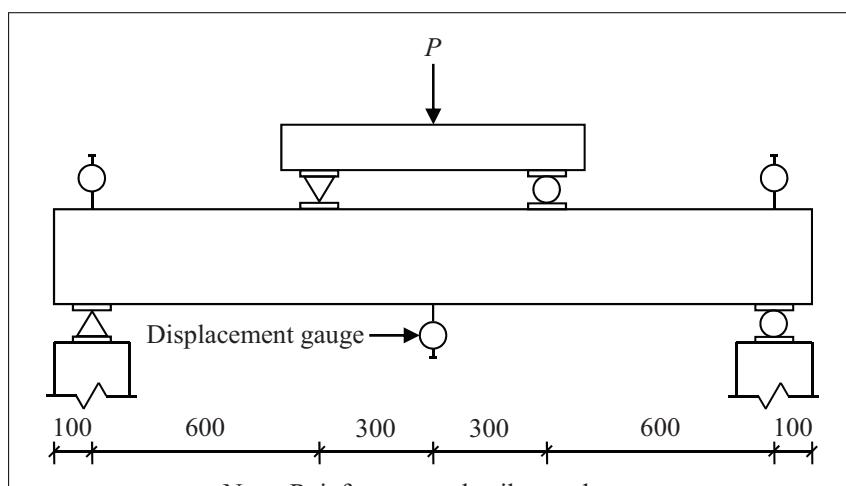

Note: Reinforcement details not shown

FIGURE 3 | Schematic view of flexural test (unit: $\mathrm{mm}$ ). postponed the cracking of concrete. As compared with the control specimens, the strengthened beams showed more cracks at smaller intervals. Failure of both strengthened specimens was initiated by yielding of main reinforcements, and followed by rupture of textile meshes in TRCC and then crushing of concrete in compression region. The bond between TRCC and strengthened specimens remained intact during the tests and there was no sign of bond failure (Figures 4B,D).

\section{Load-Deflection Relationships}

The experimentally obtained load-deflection relationships of specimens are plotted in Figure 5. In the elastic stage, the control and strengthened specimens had similar deflections. After cracking of concrete, the flexural tensile stress was carried by main reinforcements and textile meshes at cracked sections. Comparative study of the specimens reflected that, the higher the relative textile ratio was, the larger was the difference in deflections between control and strengthened specimens. When the main reinforcements yielded, the deflection increased sharply. A typical yielding plateau was observed from the loaddeflection curve of specimen L-0-1. In contrast, strengthened specimens LD-3 and LD-2 exhibited much smaller ultimate deflections due to smaller elongation of longitudinal carbon fabric bundles. Among the pair of strengthened specimens, it held true that higher relative textile ratio resulted in higher strengthening efficiency. Evidently, specimen LD-3 achieved greater improvement in both the load capacity and flexural stiffness than specimen LD-2.

Tensile strain of main reinforcements was measured and plotted in Figure 6. Benefited from the contribution by textile meshes in jointly resisting tensile stresses, the main reinforcements in strengthened specimens sustained lower tensile strain than those in control specimens under the same load level. As the relative textile ratio increased, the difference in the reinforcement strains between strengthened and control specimens enlarged. Testing of additional strengthened beam specimens would be desirable in order to quantitatively establish the relative contributions of textile meshes and main reinforcements to the load resistance at various load levels.

\section{Load Capacity and Ductility}

Cracking load $P_{c r}$, yield load $P_{y}$, and ultimate load $P_{u}$ obtained from testing of specimens are summarized in Table 4 . The cracking load and yield load are the load at which the specimens crack and main reinforcements yield, respectively. The ultimate load is the maximum load carried by the specimens. It can be seen that the load capacity of specimens achieved varying degrees of improvement by TRCC strengthening. TRCC with relative textile ratio of $2.49 \%$ could increase the cracking load, yield load and ultimate load by $26.8,7.7$, and $4.3 \%$, respectively. As the relative textile ratio was increased to $9.51 \%$, the above improvement in load resistances increased, respectively, to 86.4, 54.0 , and $25.0 \%$. The maximum percentage of improvement was observed in cracking load, followed by yield load, and ultimate load ranked the last. This is because carbon fabric bundles at beam soffit had higher elastic modulus and larger lever arm than main reinforcements. The bundles, therefore, played primary 
A

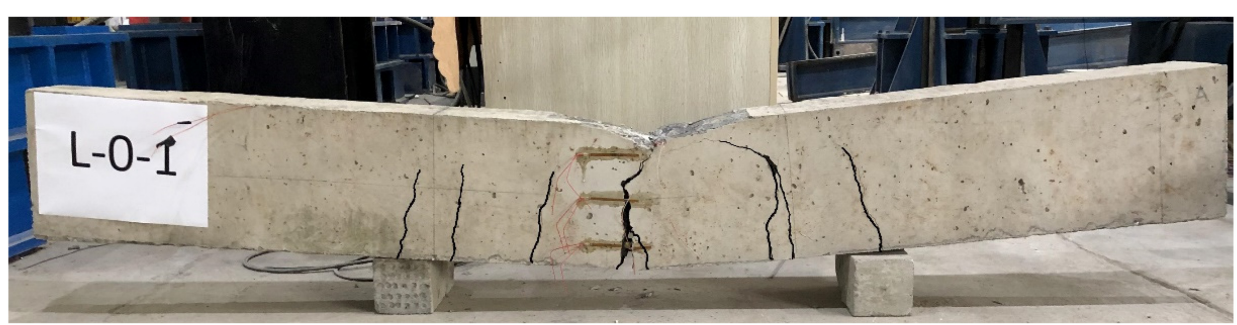

Specimen L-0-1

B

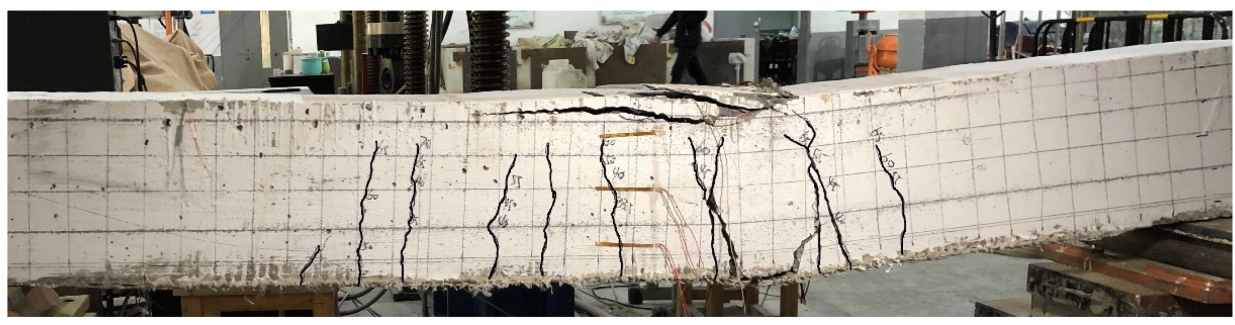

Specimen LD-3

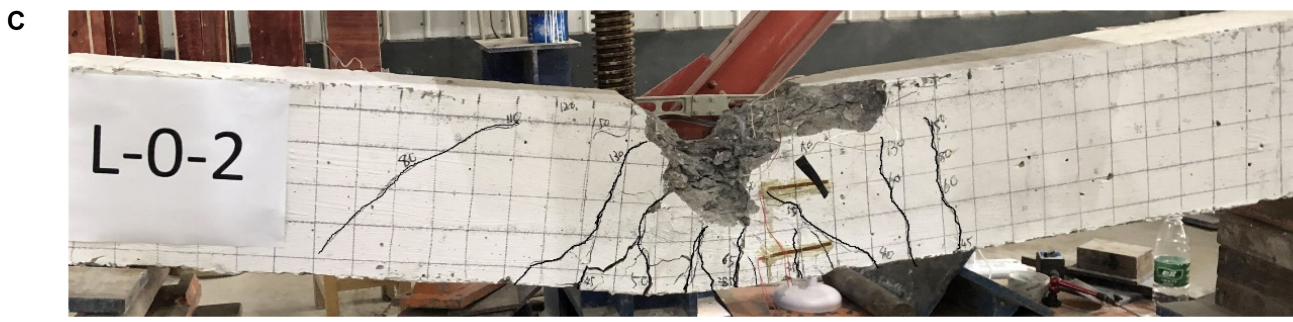

Specimen L-0-2

D

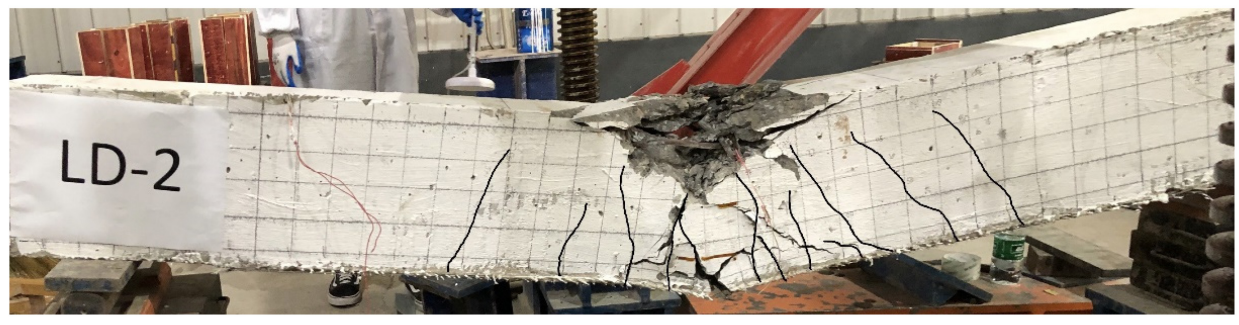

Specimen LD-2

FIGURE 4 | Failure modes of specimens. (A) Specimen L-0-1. (B) Specimen LD-3. (C) Specimen L-0-2. (D) Specimen LD-2.

role in resisting load in the initial stage of flexural test. As the load increased, the neutral axis of beams gradually shifted upwards. Main reinforcements then played more significant role in contributing to the load resistance, and the role of fabric bundles became less significant.

Corresponding to $P_{c r}, P_{y}$, and $P_{u}$, the values of cracking deflection $\Delta_{c r}$, yield deflection $\Delta_{y}$, and ultimate deflection $\Delta_{u}$ are summarized in Table 5. Experimental results indicated that TRCC strengthening enhanced stiffness and postponed both cracking and yielding of specimens. To evaluate the flexural ductility of specimens, the ductility factor is obtained as $\Delta_{u}$ divided by $\Delta_{y}$ and are reported in the last column of Table 5 . The results reflected that the ductility factor of strengthened specimen LD-3 decreased by $79 \%$ as compared with that of control specimen L-0-1. Due to the small elongation of longitudinal carbon fabric bundles, the strengthened specimen did not exhibit high ductility.

\section{PREDICTION OF FLEXURAL CAPACITY OF STRENGTHENED BEAMS}

Based on the formulation for flexural capacity of RC beams in Chinese Standard GB 50010-2010 (Ministry of Housing and Urban-Rural Development of the People's Republic of China [MOHURD], 2010) provisions, design formulae for flexural capacity of TRCC strengthened beams is proposed. Tensile strength of carbon fabric bundles is taken into consideration in 


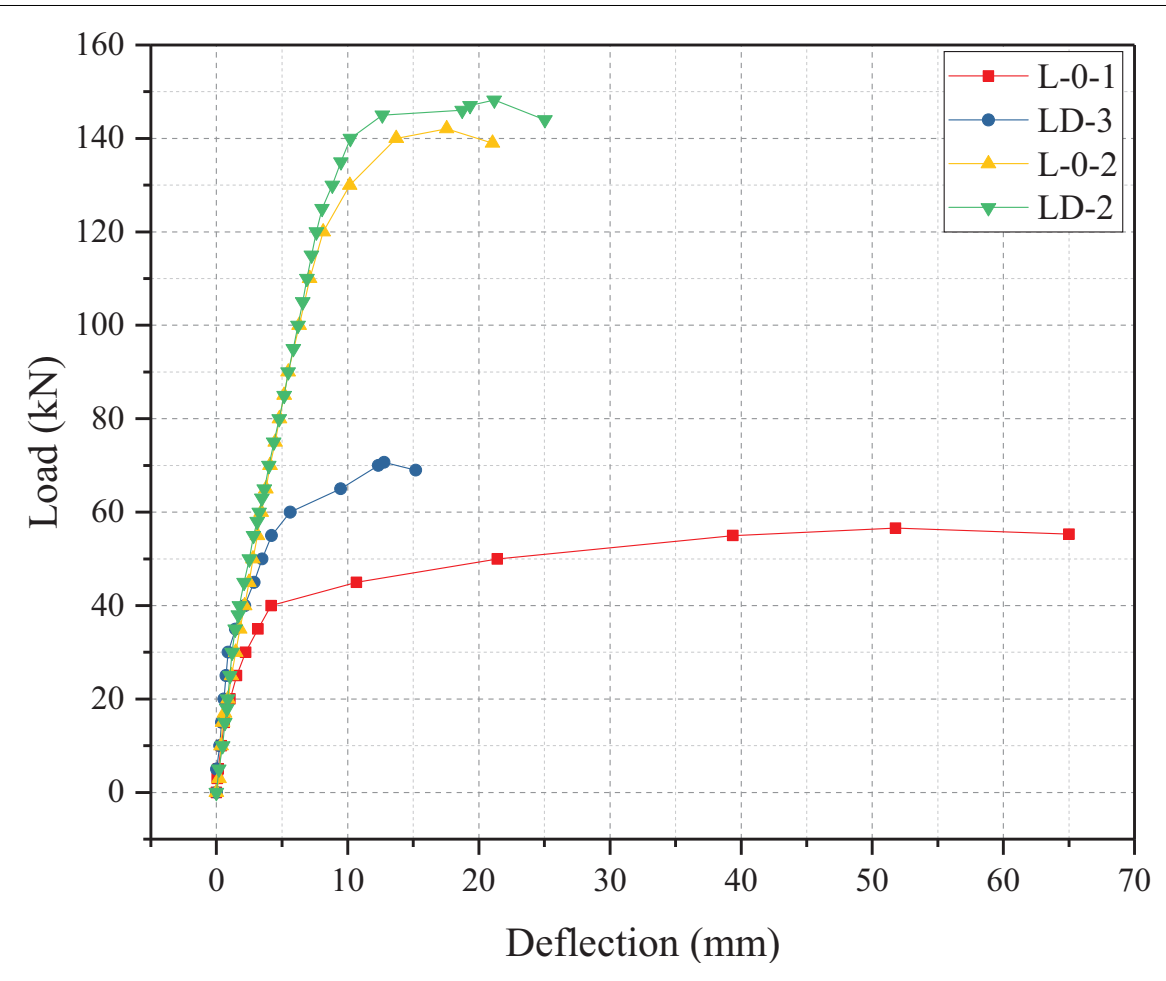

FIGURE 5 | Relationships between load and deflection.

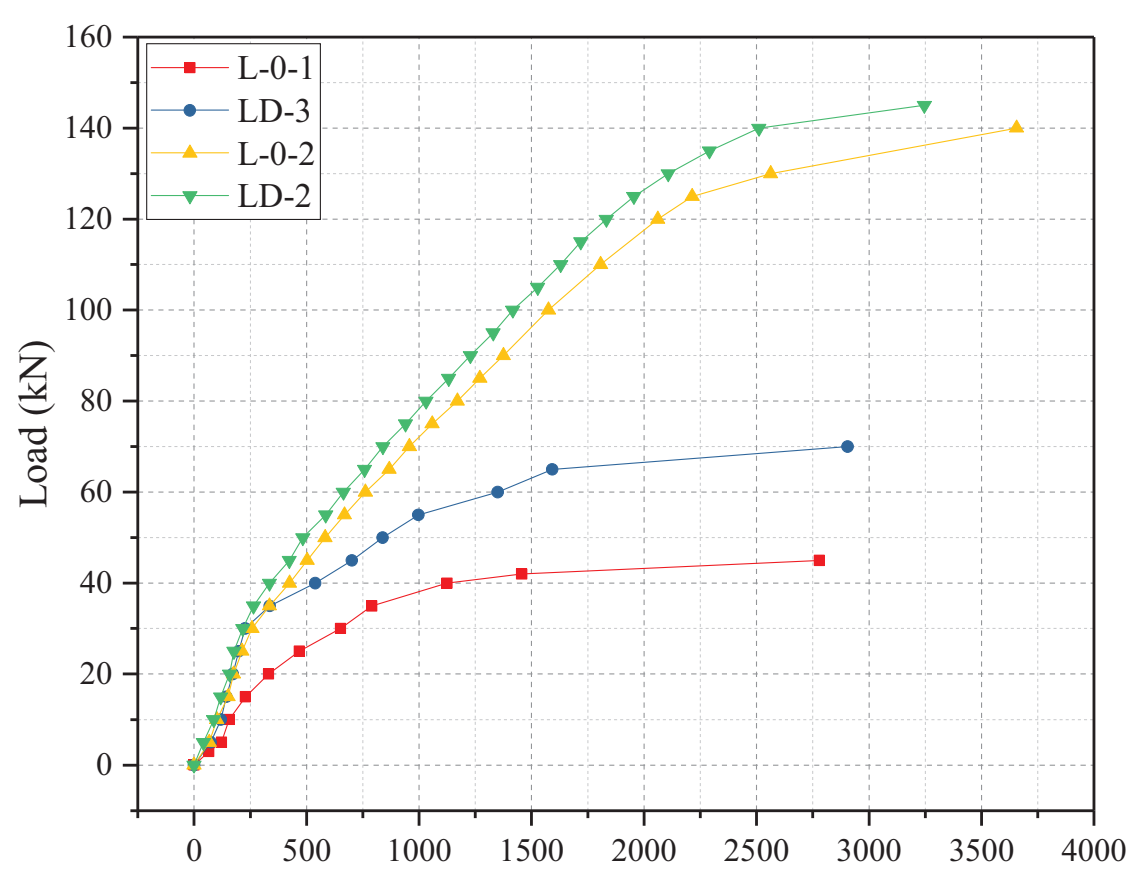

Tensile strain of main reinforcement $\left(\times 10^{-6}\right)$

FIGURE 6 | Relationships between load and tensile strain of main reinforcement. 
TABLE 4 | Cracking load, yield load, and ultimate load of specimens.

\begin{tabular}{|c|c|c|c|c|c|c|}
\hline Specimen & $P_{c r}(\mathrm{kN})$ & Increment & $P_{y}(\mathrm{kN})$ & Increment & $P_{u}(\mathrm{kN})$ & Increment \\
\hline L-0-1 & 17.51 & - & 44.28 & - & 56.57 & - \\
\hline LD-3 & 32.64 & $86.4 \%$ & 68.21 & $54.0 \%$ & 70.69 & $25.0 \%$ \\
\hline L-0-2 & 28.56 & - & 130.99 & - & 142.08 & - \\
\hline LD-2 & 36.20 & $26.8 \%$ & 141.09 & $7.7 \%$ & 148.23 & $4.3 \%$ \\
\hline
\end{tabular}

TABLE 5 | Deflections and ductility factor of specimens.

\begin{tabular}{|c|c|c|c|c|}
\hline Specimen & $\Delta_{c r}(\mathrm{~mm})$ & $\Delta_{y}(\mathrm{~mm})$ & $\Delta_{u}(\mathrm{~mm})$ & Ductility factor \\
\hline L-0-1 & 0.82 & 9.74 & 51.79 & 5.32 \\
\hline LD-3 & 1.18 & 11.32 & 12.78 & 1.13 \\
\hline L-0-2 & 1.37 & 10.51 & 17.55 & 1.67 \\
\hline LD-2 & 1.52 & 10.73 & 21.17 & 1.97 \\
\hline
\end{tabular}

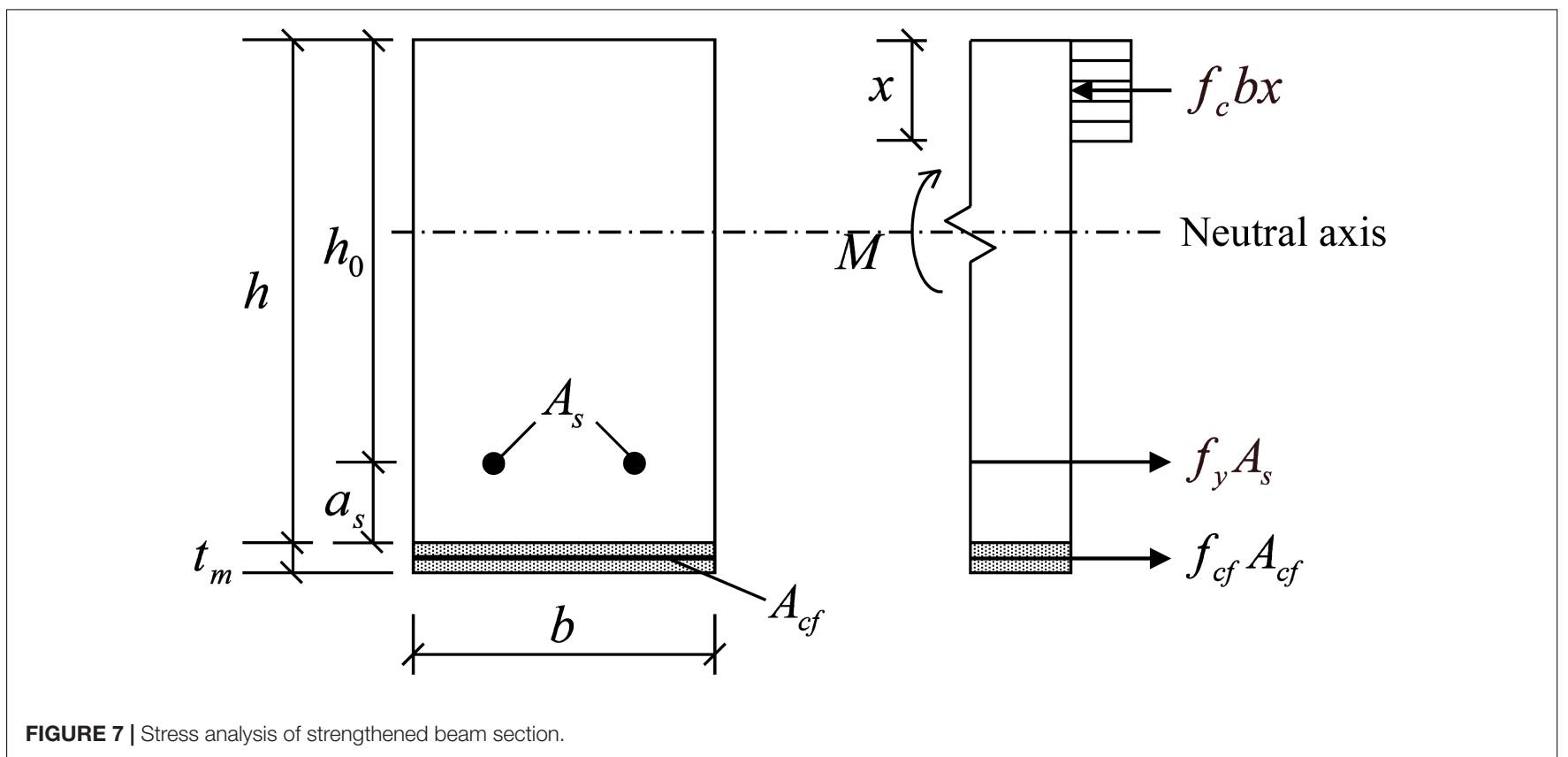

the prediction. According to the failure mode of strengthened beam, stress analysis of the beam sections is conducted, as illustrated in Figure 7.

Flexural capacity of strengthened specimens can be predicted by the following equations:

$$
\begin{gathered}
f_{c} b x=f_{y} A_{s}+f_{c f} A_{c f} \\
M_{u}=f_{c} b x\left(h+\frac{t_{m}}{2}-\frac{x}{2}\right)-f_{y} A_{s}\left(h+\frac{t_{m}}{2}-h_{0}\right)
\end{gathered}
$$

where $f_{c}$ is axial compressive strength of concrete; $b$ and $h$ are width and depth of cross section of beam, respectively, $f_{y}$ is yield strength of main reinforcements; $f_{c f}$ is tensile strength of carbon fabric bundles; $A_{s}$ and $A_{c f}$ are sectional area of main reinforcements and carbon fabric bundles, respectively, $x$ is depth of the equivalent rectangular compressive stress block of concrete; $t_{m}$ is overall thickness of TRCC system; $h_{0}$ is the effective depth (i.e., the distance from the extreme compression fiber to the centroid of main reinforcements). The above equations do not account for slippage of reinforcing bar or fabric textile mesh. In carrying out design, attention should be paid to proper reinforcement and fabric mesh detailing against slip failure.

Eqs (1) and (2) can be adopted as design formulae for predicting flexural capacity of MKPC-based TRCC strengthened RC beams. The predicted flexural capacity of specimens LD-2 and LD-3 are 44.15 and $23.84 \mathrm{kNm}$, with errors of -0.7 and $+11.1 \%$ as compared with the experimental values of 44.47 and $21.21 \mathrm{kNm}$, respectively. As reflected from Eqs (1) and (2), the tensile strength of fabric material will affect the flexural capacity of strengthened beams, further research is recommended to investigate the flexural behavior of TRCC strengthened beams using alternative fabric materials. 


\section{CONCLUSION}

In this paper, a new strengthening system, magnesium potassium phosphate cement or MKPC-based TRCC (textile reinforced cementitious composite) strengthening, was proposed to strengthen RC (reinforced concrete) beams. Two control and two strengthened specimens were produced and subjected to three-point flexural tests. Based on the experimental results, the following conclusions can be drawn:

1. MKPC-based TRCC possessed excellent bonding with substrate concrete. Strengthened beams failed due to rupture of longitudinal carbon fabric bundles in TRCC.

2. MKPC-based TRCC could effectively improve load capacity of $\mathrm{RC}$ beams. Relative textile ratio exerted crucial influence on the effectiveness of strengthening. Relative textile ratios at 2.49 and $9.51 \%$ resulted in increments of ultimate load of strengthened beams by 4.3 and $25.0 \%$, respectively.

3. The adopted TRCC strengthening system decreased the flexural ductility of RC beams due to the small elongation of longitudinal carbon fabric bundles.

Design formulae were proposed to predict the flexural capacity of beams strengthened by MKPC-based TRCC system. The prediction yielded good agreement with the experimental value of the strengthened specimen, especially for the beam with relative textile ratio of $2.49 \%$. Further research is recommended on the use of alternative fabric materials in the TRCC system for strengthening.

\section{REFERENCES}

Bernat, E., Gil, L., Roca, P., and Escrig, C. (2013). Experimental and analytical study of TRM strengthened brickwork walls under eccentric compressive loading. Constr. Build. Mater. 44, 35-47. doi: 10.1016/j.conbuildmat.2013. 03.006

Bruckner, A., Ortlepp, R., and Curbach, M. (2006). Textile reinforced concrete for strengthening in bending and shear. Mater. Struct. 39, 741-748. doi: 10.1617/ s11527-005-9027-2

Cao, D. W. (2015). Research and Technology on Bending Performance of Textile Reinforced Magnesium Phosphate Cement Matrix Composites Reinforced Defected Beams. Ph. D. Thesis, Suzhou University of Science and Technology, Suzhou.

Du, Y. B., Cao, D. W., Xun, Y., Yang, J. M., and Gao, P. W. (2017). Experimental study on shearing bonding behavior between magnesium potassium phosphate cement mortar and concrete. Build. Struct. 47, 35-38.

Escrig, C., Gil, L., Bernat, E., and Puigvert, F. (2015). Experimental and analytical study of reinforced concrete beams shear strengthened with different types of textile-reinforced mortar. Constr. Build. Mater. 83, 248-260. doi: 10.1016/j. conbuildmat.2015.03.013

Gardner, L. J., Bernal, S. A., Walling, S. A., Corkhill, C. L., Provis, J. L., and Hyatt, N. C. (2015). Characterisation of magnesium potassium phosphate cements blended with fly ash and ground granulated blast furnace slag. Cem. Concr. Res. 74, 78-87. doi: 10.1016/j.cemconres.2015.01.015

General Administration of Quality Supervision, Inspection and Quarantine of the People's Republic of China [GAQSIQ] (2017). GB/T 3362-2017: Test Methods for Tensile Properties of Carbon Fiber Multifilament. Beijing: Standards Press of China.

Gu, H. J. (2019). Slurry Design and Properties Experimental Study of High Fluidity Potassium Magnesium Phosphate Cement. Ph. D. Thesis, Jiangsu University of Science and Technology, Zhenjiang.

\section{DATA AVAILABILITY STATEMENT}

The raw data supporting the conclusions of this article will be made available by the authors, without undue reservation, to any qualified researcher.

\section{AUTHOR CONTRIBUTIONS}

C-JZ: conceptualization, data curation, funding acquisition, investigation, methodology, project administration, resources, visualization, and writing - original draft. SF: data interpretation, formal analysis, investigation, methodology, visualization, and writing - original draft. PN: data interpretation, funding acquisition, resources, supervision, validation, and writing review and editing. IP: conceptualization, formal analysis, project administration, resources, supervision, and validation. J-JC: data curation, data interpretation, resources, software, validation, and visualization. All authors contributed to the article and approved the submitted version.

\section{FUNDING}

This work was supported from the National Natural Science Foundation of China (Project Nos. 51478408 and 51578475) and the Research Executive Agency of the European Commission (Project No. 751461).

Hegger, J., and Voss, S. (2008). Investigations on the bearing behaviour and application potential of textile reinforced concrete. Eng. Struct. 30, 2050-2056. doi: 10.1016/j.engstruct.2008.01.006

Holschemacher, K. (2020). Application of textile reinforced concrete in precast concrete industry. IOP Conf. Ser. Mater. Sci. Eng. 753:042086. doi: 10.1088/ $1757-899 \mathrm{x} / 753 / 4 / 042086$

Holschemacher, K., Meßerer, D., and Heiden, B. (2018). "Test method for curvature-dependent tensile strength reduction of textile reinforced concrete (TRC)," in Proceeding of the 5th fib Congress, Melbourne, Australia, (Melbourne, VI: FIB).

International Organization for Standardization (2009). ISO 679-2009: Cement Test Methods - Determination of Strength. Geneva: International Organization for Standardization.

Kolsch, H. (1998). Carbon fiber cement matrix (CFCM) overlay system form masonry strengthening. J. Compos. Constr. 2, 105-109. doi: 10.1061/(asce) 1090-0268(1998)2:2(105)

Kong, K., Mesticou, Z., Michel, M., Larbi, A., and Junes, A. (2017). Comparative characterization of the durability behaviour of textile reinforced concrete (TRC) under tension and bending. Compos. Struct. 179, 107-123. doi: 10.1016/j. compstruct.2017.07.030

Le Rouzic, M., Chaussadent, T., Stefan, L., and Saillio, M. (2017). On the influence of $\mathrm{Mg} / \mathrm{P}$ ratio on the properties and durability of magnesium potassium phosphate cement pastes. Cem. Concr. Res. 96, 27-41. doi: 10.1016/j.cemconres. 2017.02.033

Mesticou, Z., Bui, L., Junes, A., and Larbi, A. (2017). Experimental investigation of tensile fatigue behaviour of textile-reinforced concrete (TRC): effect of fatigue load and strain rate. Compos. Struct. 160, 1136-1146. doi: 10.1016/j.compstruct. 2016.11.009

Ministry of Housing and Urban-Rural Development of the People's Republic of China [MOHURD] (2010). GB 50010-2010: Code for Design of Concrete Structures. Beijing: China Architecture \& Building Press. 
Ministry of Industry and Information Technology of the People's Republic of China [MOIIT] (2019). JC/T 2537-2019: Magnesium Phosphate Repairing Mortar. Beijing: China Building Materials Press.

Mobasher, B. (2019). Mechanics of Fiber and Textile Reinforced Cement Composites. New York: CRC Press.

Naaman, A. E. (2010). "Textile reinforced cement composites: competitive status and research directions," in Proceedings, International RILEM Conference on Material Science, ed. W. Brameshuber (Aachen: RILEM Publications SARL), $3-22$.

Ortlepp, R., and Ortlepp, S. (2017). Textile reinforced concrete for strengthening of $\mathrm{RC}$ columns: a contribution to resource conservation through the preservation of structures. Constr. Build. Mater. 132, 150-160. doi: 10.1016/j.conbuildmat. 2016.11.133

Peled, A., Bentur, A., and Mobasher, B. (2019). Textile Reinforced Concrete. New York, NY: CRC Press.

Raoof, S. M., Koutas, L. N., and Bournas, D. A. (2017). Textile-reinforced mortar (TRM) versus fibre-reinforced polymers (FRP) in flexural strengthening of RC beams. Constr. Build. Mater. 151, 279-291. doi: 10.1016/j.conbuildmat.2017. 05.023

Tran, M. T., Vu, X. H., and Ferrier, E. (2018). Experimental and analytical analysis of the effect of fiber treatment on the thermomechanical behavior of continuous carbon textile subjected to simultaneous elevated temperature and uniaxial tensile loadings. Constr. Build. Mater. 183, 32-45. doi: 10.1016/j.conbuildmat.2018. 06.114

Triantafillou, T. C. (2016). Textile Fibre Composites in Civil Engineering. Duxford: Woodhead Publishing.

Xu, S. L., Shen, L., and Wang, J. (2016). The high-temperature resistance performance of TRC thin-plates with different cementitious materials: experimental study. Constr. Build. Mater. 115, 506-519. doi: 10.1016/j. conbuildmat.2016.04.070

Xun, Y., Zhi, Z. D., and Zhang, Q. (2010). Experimental research on flexural behavior of reinforced concrete beams strengthened with textile reinforced concrete sheets. J. Build. Struct. 31, 70-76.
Yang, J. M., Wang, L. M., Jin, C., and Sheng, D. (2020). Effect of fly ash on the corrosion resistance of magnesium potassium phosphate cement paste in sulfate solution. Constr. Build. Mater. 237:117639. doi: 10.1016/j.conbuildmat.2019. 117639

Yin, S. P. (2010). Research on TRC Mechanical Behavior and Flexural Performance of Concrete Beam Reinforced with TRC. Doctoral Thesis, Dalian University of Technology, Dalian.

Yin, S. P., Jing, L., Yin, M. T., and Wang, B. (2019). Mechanical properties of textile reinforced concrete under chloride wet-dry and freeze-thaw cycle environments. Cem. Concr. Comp. 96, 118-127. doi: 10.1016/j.cemconcomp. 2018.11.020

Yin, S. P., Sheng, J., Lv, H. L., and Jia, S. (2015). Flexural behavior of RC beams strengthened with TRC under static loading. Chn. J. Highway Transport. 28, $45-53$.

Zhang, Q. (2009). Experimental Study on Flexural Behavior of Reinforced Concrete Beams Strengthened with Textile Reinforced Concrete. Ph. D. Thesis, Jiangsu University, Zhenjiang.

Zhi, Z. D., Chen, H., Xun, Y., Yang, J. M., and Du, Y. B. (2017). Experimental research on flexural behavior of RC beams strengthened with E-glass textile reinforced fine aggregate concrete sheets used magnesium phosphate cement. Build. Struct. 47, 89-93.

Conflict of Interest: The authors declare that the research was conducted in the absence of any commercial or financial relationships that could be construed as a potential conflict of interest.

The handling Editor declared a past co-authorship with one of the authors SF.

Copyright $\odot 2020 \mathrm{Zhu}$, Fang, Ng, Pundiene and Chen. This is an open-access article distributed under the terms of the Creative Commons Attribution License (CC BY). The use, distribution or reproduction in other forums is permitted, provided the original author(s) and the copyright owner(s) are credited and that the original publication in this journal is cited, in accordance with accepted academic practice. No use, distribution or reproduction is permitted which does not comply with these terms. 